\title{
(a) Effect of losartan and spironolactone on OPEN ACCESS triglyceride-rich lipoproteins in diabetic
nephropathy
}

Anand Srivastava, ${ }^{1}$ Beverley Adams-Huet, ${ }^{2,3}$ Gloria L Vega, ${ }^{4}$ Robert D Toto ${ }^{2}$

- Additional material is published online only. To view please visit the journal online (http://dx.doi.org/10. 1136/jim-2016-000102).

${ }^{1}$ Division of Renal Medicine, Brigham \&Women's Hospital, Boston,

Massachusetts, USA

${ }^{2}$ Department of Internal

Medicine, University of Texas Southwestern Medical

Center, Dallas, Texas, USA

${ }^{3}$ Department of Clinical

Sciences, University of Texas

Southwestern Medical

Center, Dallas, Texas, USA

${ }^{4}$ Center for Human

Nutrition, University of Texas

Southwestern Medical

Center, Dallas, Texas, USA

\section{Correspondence to}

Dr Robert D Toto

Department of Internal

Medicine, University of Texas

Southwestern, 5323 Harry

Hines Blvd, Dallas, TX

75390, USA:

Robert.Toto@

UTSouthwestern.edu

Accepted 16 May 2016

Published Online First

7 July 2016

Copyright (C) 2016 American Federation for Medical Research

\section{ABSTRACT}

Angiotensin-converting enzyme inhibitors (ACEi) and angiotensin receptor blockers (ARBs) can improve dyslipidemia in patients with diabetes and albuminuria. Whether combined ACEi+ARB or ACEi +mineralocorticoid receptor blockade improves dyslipidemia is not known. We hypothesized long-term administration of either losartan $100 \mathrm{mg}$ or spironolactone $25 \mathrm{mg}$ once daily added onto lisinopril $80 \mathrm{mg}$ once daily would improve dyslipidemia in diabetic nephropathy (DN). We measured lipid levels, very-low-density (V), intermediate-density (I), low-density (LDL), highdensity (HDL) lipoprotein, LDL particle size with their respective cholesterol (C) and apolipoprotein B levels $(\mathrm{ApoB})$, and urine albumin/creatinine ratio (UACR) at 12-week interval during a 48-week randomized, double-blind placebo-controlled trial in 81 patients with DN. Plasma lipids and lipoprotein C were analyzed enzymatically and Apo B was determined chemically. Data were analyzed by mixed model repeated measures. $\triangle U A C R$ differed among treatment arms (placebo $-24.6 \%$, los $-38.2 \%$, spiro $-51.6 \%, p=0.02$ ). No correlation existed between $\triangle U A C R$ and $\triangle T G$ or any of the lipid or lipoprotein measurements. Compared with placebo losartan, but not spironolactone, decreased TG $(-20.9 \%$ vs $+34.3 \%, p<0.01), V+I C(-18.8 \%$ vs $+21.3 \%, \mathrm{p}<0.01)$, and $\mathrm{V}+\mathrm{I}-\mathrm{ApoB}(-13.2 \%$ vs $+21 \%, p<0.01)$. There were no significant changes in body weight, HbA1c or other lipoprotein variables. We conclude losartan improves dyslipidemia in patients with DN. We speculate the mechanism improved clearance of VLDL and remnant lipoproteins.

Trial registration number NCT00381134; Results.

\section{INTRODUCTION}

The leading cause of end-stage renal disease (ESRD) worldwide is diabetic nephropathy (DN). ${ }^{1}$ Poor control of albuminuria and hypertension associated with diabetes evidenced by macroalbuminuria are risk factors for progression of chronic kidney disease (CKD) and cardiovascular disease (CVD). ${ }^{2-4}$ Albuminuric patients are at almost a sixfold risk of increased incidence of myocardial infarction in the renal population. $^{5} 6$ Diabetes-related dyslipidemia results in lipid abnormalities that are highly atherogenic and likely determinants of CVD.?

\section{Significance of this study}

\section{What is already known about this} subject?

- Poor control of albuminuria and hypertension in diabetes with macroalbuminuria are risk factors for progression of chronic kidney disease and cardiovascular disease.

- Dyslipidemia is associated with severe proteinuria in nephrotic syndrome and non-nephrotic range proteinuria in patients with diabetes.

- Angiotensin-converting enzyme inhibitors (ACEi) and angiotensin-receptor blockers (ARBs) reduce albuminuria, lower blood pressure, and slow progression of diabetic nephropathy.

\section{What are the new findings?}

- Reductions in albuminuria with losartan or spironolactone did not improve dyslipidemia.

- Losartan improved dyslipidemic profiles in triglycerides and triglyceride-rich lipoproteins.

- The mechanism may be reduction of hepatic VLDL production or improving VLDL catabolism.

How might these results change the focus of research or clinical practice?

- Amelioration of albuminuria and dyslipidemia with the use of an ARB could be an important tool in reducing the risk of progression to end-stage renal disease (ESRD) and developing cardiovascular complications. Future studies should attempt to elucidate whether potent triglyceride lowering using an ARB coupled with remnant lipoprotein-lowering agents improves cardiovascular outcomes in patients with diabetic nephropathy.

Additionally, dyslipidemia is associated with severe proteinuria in nephrotic syndrome, and non-nephrotic range proteinuria in patients with diabetes. ${ }^{8-11}$ The mechanism of dyslipidemia in nephrotic patients is unclear but has 
been postulated to result from increased synthesis and decreased catabolism of lipoproteins. ${ }^{12}$ Nephrotic patients have elevated levels of TGs, low-density lipoprotein (LDL) cholesterol, and very-low-density lipoproteins (VLDLs) with their respective apolipoprotein B (ApoB) particles especially in those patients with massive proteinuria. ${ }^{10} 13$ Diabetic patients with non-nephrotic range proteinuria may have differential dyslipidemia comprised of increasing ApoB, lipoprotein A, and TG. ${ }^{11}$ Diabetic patients may have an increased risk of CKD progression and need for renal replacement therapy with elevated TG in the presence of overt proteinuria. ${ }^{14} 15$

Angiotensin-converting enzyme inhibitors (ACEi) and angiotensin-receptor blockers (ARB) reduce albuminuria, lower blood pressure, and slow the progression of $\mathrm{DN} .^{16}$ One study shows that ACEi results in reduction of total cholesterol and LDL in conjunction with a partial reduction of proteinuria in nephrotic individuals. ${ }^{17}$ Some studies suggest a dose-response relationship between lipid reduction and antiproteinuric efficacy in experimental animals and humans. However, these studies represented a small number of patients and used low doses of ACEi. ${ }^{18} 19$

Improving dyslipidemia may provide benefit by improving the cardiovascular risk and reduce the risk of CKD progression in patients with DN. Adding either an ARB or a mineralocorticoid receptor antagonist (MRA) onto maximally dosed ACEi therapy regimen further improves albuminuria in patients with DN. MRA added onto ACEi regimen improved albuminuria more than ARB. ${ }^{20}$ We hypothesized that long-term administration of losartan $100 \mathrm{mg}$ or spironolactone $25 \mathrm{mg}$ once daily added onto lisinopril $80 \mathrm{mg}$ once daily improves dyslipidemia in patients with DN.

\section{MATERIALS AND METHODS}

This trial was conducted between August 2003 and 2007, and the specific aim was to determine whether antiproteinuric effects of losartan or spironolactone were independent of blood pressure lowering in patients with DN. The results of the trial have been published. ${ }^{20}$ The trial was conducted at the University of Texas Southwestern Medical Center and the protocol was approved by the University's Institutional Review Board and in adherence with the Declaration of Helsinki (ClinicalTrials.gov Identifier: NCT00381134).

Briefly, the study was a double-blind, placebo-controlled trial in 81 patients with diabetes, hypertension, and albuminuria (urine albumin-to-creatinine ratio (UACR)) $\geq 300 \mathrm{mg} / \mathrm{g}$ confirmed by two 24-hour urine samples while on their maximum dose ACEi at the end of the run-in period). After qualification, patients underwent a run-in period of 48 weeks where they were initiated on a dose of lisinopril (20-40 mg daily) substituted for the patient's prior ACEi or $\mathrm{ARB}$ and gradually increased to a maximum dose of $80 \mathrm{mg}$ daily (supplement figure 2). Additional antihypertensive drugs were added to reach a goal of systolic blood pressure $<130 \mathrm{~mm} \mathrm{Hg}$ prior to randomization. Stratified by the type of diabetes, subjects were then randomly assigned to placebo, losartan (100 mg daily), or spironolactone (25 mg daily) for 48 weeks while they were taking lisinopril. Blood and urine albumin, urea, creatinine, electrolytes, hemoglobin $\mathrm{A} 1 \mathrm{c}(\mathrm{HbA} 1 \mathrm{c})$, and ambulatory blood pressure were measured at baseline, 24, and 48 weeks. ${ }^{20}$ We maintained study subjects on their current doses of hypolipidemic agents throughout the study, given the potential to reduce lipids and albuminuria. In addition, a constant diet was prescribed to minimize the potential confounding effect of diet on plasma lipid and lipoprotein levels.

This report focuses on the effects of these therapies on plasma lipids and lipoproteins, a prespecified secondary outcome of the trial. Accordingly, levels of plasma total cholesterol, triglycerides, and HDL cholesterol were measured at baseline, 24 and 48 weeks as detailed previously. Levels of VLDL plus intermediate-density lipoprotein (IDL) cholesterol were carried out after isolation of the lipoproteins by ultracentrifugation. LDL cholesterol concentration was calculated as the difference between total cholesterol concentration minus the sum of VLDL plus IDL plus HDL cholesterol concentrations. Total apolipoprotein (ApoB) level was measured chemically. ${ }^{21}$ The coefficients of intra-assay and interassay variation for the enzymatic methods used to quantify lipids are $<3 \%$. This is also true for the chemical assay for ApoB.

LDL sizes were measured with the Lipoprint System (Quantimetrix Corporation, Redondo Beach, California, USA). Seven species of LDL can be identified by this method. The coefficients of interassay and intra-assay variation for this assay were $\sim 2 \%$. In addition to the seven LDL species, LDL particles were divided into large and small species; the cut point for separation between large and small particles was a particle size of $263 \AA$, as detailed previously. ${ }^{21} 22$ The areas for large LDL $(\geq 263 \AA)$ and small LDL (<263 Å) were calculated. A large-to-small LDL ratio of $>1.0$ corresponds approximately to lipoprotein phenotype pattern $\mathrm{A}$, whereas a ratio of $<1.0$ corresponds approximately to pattern B. Predominance of large LDL is classified as Type $A$ and predominance of small dense LDL is classified as Type B. Type B is associated with moderate-to-severe hypertriglyceridemia and/or low HDL cholesterol. Type B is also prevalent in subjects with insulin resistance.

\section{Statistical analyses}

An intention to treat analysis was performed including 80 of the 81 randomized subjects, (one subject did not complete the baseline evaluation and never received the study drug). Repeated measures analyses utilizing all lipid and lipoprotein measurements obtained during the 48 weeks of treatment were conducted using a mixed linear model analysis of covariance approach. This mixed-effect linear model consisted of a treatment effect, study week, and baseline value as a covariate, with subject modeled as a random effect. Comparisons between groups were made using the least square contrasts derived from these mixed-effect models. Positively skewed variables were log transformed prior to analysis. Associations between variables were assessed with Spearman correlation coefficients $\left(r_{s}\right)$. All tests were two-tailed with a $\mathrm{p}$ value $<0.05$ considered significant. Statistical analyses were performed with SAS V.9.2 (SAS Institute, Cary, North Carolina, USA).

\section{RESULTS}

Baseline characteristics were similar among the randomized groups (table 1). The mean 24-hour (UACR) was $\sim 1000 \mathrm{mg} / \mathrm{g}$. There were no differences in blood pressure, 
Table 1 Baseline characteristics

\begin{tabular}{|c|c|c|c|}
\hline Characteristic & Placebo, $n=27$ & Losartan, n=26 & Spironolactone, $n=27$ \\
\hline Female, number (\%) & $15(55.6)$ & $13(50.0)$ & $14(51.9)$ \\
\hline Age, years & $49.3 \pm 8.8$ & $52.3 \pm 9.1$ & $51.7 \pm 9.3$ \\
\hline BMI $\left(k g / m^{2}\right)$ & $32.3 \pm 7.1$ & $30.3 \pm 5.4$ & $33.7 \pm 7.1$ \\
\hline Duration of diabetes, years & $14.4 \pm 9.6$ & $17.0 \pm 7.7$ & $17.0 \pm 9.1$ \\
\hline Statin therapy, number (\%) & $19(70.4)$ & $17(65.4)$ & $18(66.7)$ \\
\hline Serum creatinine, mg/dL & $1.4 \pm 0.7$ & $1.7 \pm 0.7$ & $1.8 \pm 0.9$ \\
\hline Urine albumin to creatinine ratio $(\mathrm{mg} / \mathrm{g})$ & 917 (633 to 1329) & 897 (611 to 1316$)$ & 1094 (758 to 1579$)$ \\
\hline Normalized protein catabolic rate, g/kg/days & $0.97 \pm 0.21$ & $1.07 \pm 0.26$ & $0.91 \pm 0.21$ \\
\hline Hemoglobin A1c, \% & $8.1 \pm 1.3$ & $7.6 \pm 1.3$ & $7.4 \pm 1.6$ \\
\hline Total cholesterol, mg/dL & $189 \pm 49$ & $198 \pm 75$ & $176 \pm 44$ \\
\hline LDL cholesterol, mg/dL & $95 \pm 38$ & $100 \pm 45$ & $75 \pm 29$ \\
\hline HDL cholesterol, mg/dL & $43 \pm 10$ & $46 \pm 15$ & $45 \pm 11$ \\
\hline Triglycerides, mg/dL & 183 (145 to 232 ) & 175 (136 to 225$)$ & 191 (156 to 235) \\
\hline Triglycerides/HDL & 4.3 (3.3 to 5.7$)$ & $4.0(2.9$ to 5.6$)$ & 4.3 (3.4 to 5.5$)$ \\
\hline VLDL+IDL-C, mg/dL & 41.8 (32.3 to 54.2$)$ & 40.0 (30.7 to 52.1$)$ & 47.3 (38.2 to 58.6$)$ \\
\hline VLDL+IDL Apo-B, mg/dL & 31.3 (24.4 to 40.2$)$ & 28.3 (22.8 to 35.2$)$ & $33.5(28.0$ to 40.1$)$ \\
\hline \multicolumn{4}{|l|}{ 24-hour Ambulatory BP, mm Hg } \\
\hline Systolic & $138 \pm 15$ & $143 \pm 15$ & $135 \pm 11$ \\
\hline Diastolic & $75 \pm 9$ & $75 \pm 9$ & $71 \pm 9$ \\
\hline \multicolumn{4}{|l|}{ Concomitant antihypertensives (week 0 ) } \\
\hline Diuretic & $23(85.2)$ & $23(88.5)$ & $27(96.3)$ \\
\hline$\beta$-Blocker & $19(70.4)$ & $17(63.4)$ & $21(77.8)$ \\
\hline$\alpha$-Blocker & $8(29.6)$ & $8(30.8)$ & $7(25.9)$ \\
\hline Central adrenergic agonist & $2(7.4)$ & $3(11.5)$ & $3(11.1)$ \\
\hline Vasodilator & $1(3.7)$ & $0(0)$ & $0(0)$ \\
\hline \multicolumn{4}{|l|}{ Concomitant antihypertensives (week 1-48) } \\
\hline Diuretic & $25(92.6)$ & $24(92.3)$ & $25(92.6)$ \\
\hline$\beta$-Blocker & $21(77.8)$ & $22(84.6)$ & $22(81.5)$ \\
\hline$\alpha$-Blocker & $15(55.6)$ & $16(61.5)$ & $13(48.2)$ \\
\hline Central adrenergic agonist & $9(33.3)$ & $11(42.3)$ & $5(18.5)$ \\
\hline Vasodilator & $2(7.4)$ & $2(7.7)$ & $0(0)$ \\
\hline
\end{tabular}

protein intake, sodium intake, or glycemia among groups during the 48 weeks of the study. There were no differences in baseline blood pressure or UACR when comparing patients with type 1 and type 2 diabetes. On average, three add-on antihypertensive agents were used to achieve and maintain the blood pressure (BP) goal in all three groups. The antihypertensive regimen included a diuretic agent in $90-95 \%$ in each arm. Overall, there was a significant difference in the per cent change in UACR between the three treatment groups in the primary study $(\mathrm{p}=0.02)$ with spironolactone having a significantly greater reduction in UACR compared with placebo. At 48 weeks, there was no change from baseline in the placebo group $(-24.6 \%$, $\mathrm{p}=0.08)$. In contrast, UACR decreased significantly from baseline in losartan $(-38.2 \%, \mathrm{p}<0.01)$ and spironolactone groups $(-51.6 \%, \mathrm{p}<0.01) .^{20}$

\section{Lipids}

Plasma TG levels, the TG to HDL-cholesterol ratio and VLDL-plus IDL-cholesterol were significantly decreased in subjects treated with losartan as compared with spironolactone and placebo as follows: TG $(\mathrm{p}<0.01), \mathrm{TG} / \mathrm{HDL}$ $(\mathrm{p}<0.01)$, very-low $(\mathrm{V})$ and intermediate $(\mathrm{I})$ density lipoproteins $(\mathrm{V}+\mathrm{I}-\mathrm{C}, \mathrm{p}<0.01)$, and respective Apo B levels (V $+\mathrm{I}-\mathrm{ApoB}, \mathrm{p}<0.01$; table 2). Similarly, patients assigned to losartan compared with spironolactone had lower levels of TG $(p=0.01), T G / H D L(p=0.02), V+I-C(p=0.03)$, and $\mathrm{V}+\mathrm{I}-\mathrm{ApoB}(\mathrm{p}=0.01$; figure 1$)$.

Total cholesterol did not significantly differ between treatment groups $(p=0.06)$. The per cent change from week 0 to week 48 was $+25.9 \%$ in the placebo, $-7 \%$ in losartan, and $+0.7 \%$ in spironolactone. Although the losartan group (-8.4\%) decreased the total ApoB when compared with placebo $(+9.6 \%)$ and spironolactone $(+16.9 \%)$, the groups were not statistically significant $(\mathrm{p}=0.06)$. When comparing non-HDL profiles, losartan $(-11.2 \%)$, placebo $(+6.1 \%)$, and spironolactone $(-0.6 \%)$ treatment differences were not observed $(p=0.30)$.

Changes in plasma HDL were not different between treatment groups $(p=0.12)$, and all treatment groups decreased slightly from baseline (placebo $-3.5 \%$, losartan $-2.3 \%$, spironolactone $-7.4 \%)$.

Changes in LDL were not significantly different between treatment groups. LDL-ApoB changes at 48 weeks were 
Table 2 Lipids and lipoproteins during treatment

\begin{tabular}{|c|c|c|c|c|c|}
\hline \multirow[b]{2}{*}{ Variable } & \multirow[b]{2}{*}{ Treatment } & \multicolumn{3}{|l|}{ Week } & \multirow[b]{2}{*}{ p Value* } \\
\hline & & 0 & 24 & 48 & \\
\hline Sample sizet & $\begin{array}{l}\text { Placebo } \\
\text { Losartan } \\
\text { Spironolactone }\end{array}$ & $\begin{array}{l}27 \\
26 \\
27\end{array}$ & $\begin{array}{l}22 \\
23 \\
20\end{array}$ & $\begin{array}{l}21 \\
21 \\
17\end{array}$ & \\
\hline Total cholesterol, mg/dL & $\begin{array}{l}\text { Placebo } \\
\text { Losartan } \\
\text { Spironolactone }\end{array}$ & $\begin{array}{l}189(49) \\
198(75) \\
176(44)\end{array}$ & $\begin{array}{l}187(40) \\
179(54) \\
185(56)\end{array}$ & $\begin{array}{l}189(54) \\
179(53) \\
173(42)\end{array}$ & 0.06 \\
\hline LDL cholesterol, mg/dL & $\begin{array}{l}\text { Placebo } \\
\text { Losartan } \\
\text { Spironolactone }\end{array}$ & $\begin{array}{r}95(38) \\
100(45) \\
75(29)\end{array}$ & $\begin{array}{l}96(32) \\
92(39) \\
82(38)\end{array}$ & $\begin{array}{l}97(38) \\
93(47) \\
76(31)\end{array}$ & 0.40 \\
\hline HDL cholesterol, mg/dL & $\begin{array}{l}\text { Placebo } \\
\text { Losartan } \\
\text { Spironolactone }\end{array}$ & $\begin{array}{l}43(10) \\
46(15) \\
45(11)\end{array}$ & $\begin{array}{l}47(14) \\
42(13) \\
40(11)\end{array}$ & $\begin{array}{l}42(13) \\
43(12) \\
41(10)\end{array}$ & 0.12 \\
\hline Triglycerides, mg/dL & $\begin{array}{l}\text { Placebo } \\
\text { Losartan } \\
\text { Spironolactone }\end{array}$ & $\begin{array}{l}183 \text { (145 to } 232) \\
175 \text { (136 to } 225) \\
191 \text { (156 to } 235)\end{array}$ & $\begin{array}{l}178 \text { (146 to } 217) \\
170(128 \text { to } 227) \\
241(172 \text { to } 339)\end{array}$ & $\begin{array}{l}192 \text { (148 to } 249) \\
150(116 \text { to } 194) \\
219(162 \text { to } 294)\end{array}$ & $<0.01$ \\
\hline Triglycerides/HDL & $\begin{array}{l}\text { Placebo } \\
\text { Losartan } \\
\text { Spironolactone }\end{array}$ & $\begin{array}{l}4.3(3.3 \text { to } 5.7) \\
4.0(2.9 \text { to } 5.6) \\
4.3(3.4 \text { to } 5.5)\end{array}$ & $\begin{array}{l}4.0(3.0 \text { to } 5.3) \\
4.2(2.9 \text { to } 6.1) \\
6.2(4.1 \text { to } 9.4)\end{array}$ & $\begin{array}{l}4.7(3.3 \text { to } 6.7) \\
3.6(2.6 \text { to } 5.1) \\
5.5(3.8 \text { to } 8.0)\end{array}$ & $<0.01$ \\
\hline $\mathrm{VLDL}+\mathrm{IDL}-\mathrm{C}, \mathrm{mg} / \mathrm{dL}$ & $\begin{array}{l}\text { Placebo } \\
\text { Losartan } \\
\text { Spironolactone }\end{array}$ & $\begin{array}{l}41.8 \text { (32.3 to } 54.2) \\
40.0 \text { (30.7 to } 52.1) \\
47.3(38.2 \text { to } 58.6)\end{array}$ & $\begin{array}{l}38.9 \text { (30.7 to } 49.4) \\
35.8 \text { (26.4 to } 48.7) \\
50.3 \text { (36.2 to } 69.7)\end{array}$ & $\begin{array}{l}40.3 \text { (29.9 to } 54.2) \\
35.7(27.5 \text { to } 46.3) \\
46.5(33.6 \text { to } 64.2)\end{array}$ & $<0.01$ \\
\hline VLDL+IDL Apo-B, mg/dL & $\begin{array}{l}\text { Placebo } \\
\text { Losartan } \\
\text { Spironolactone }\end{array}$ & $\begin{array}{l}31.3 \text { (24.4 to } 40.2) \\
28.3(22.8 \text { to } 35.2) \\
33.5(28.0 \text { to } 40.1)\end{array}$ & $\begin{array}{l}28.4 \text { (22.7 to } 35.5) \\
25.3(19.6 \text { to } 32.8) \\
34.2(26.8 \text { to } 43.5)\end{array}$ & $\begin{array}{l}30.1(23.0 \text { to } 39.5) \\
26.7(21.0 \text { to } 33.8) \\
33.3(25.2 \text { to } 44.0)\end{array}$ & $<0.01$ \\
\hline
\end{tabular}

$+3.9 \%,-9.6 \%$, and $16.9 \%$ for placebo, losartan, and spironolactone, respectively $(\mathrm{p}=0.38$ between treatments). LDL particle size was similar among the three treatment groups.

No significant correlations were observed between the per cent change from baseline in UACR versus TG at month $24 \quad\left(\mathrm{r}_{\mathrm{s}}=0.21, \mathrm{p}=0.13\right)$ or month $48 \quad\left(\mathrm{r}_{\mathrm{s}}=0.22\right.$, $\mathrm{p}=0.10$ ), all subjects combined, or by treatment (data not shown).

\section{DISCUSSION}

The principal new finding in this study is that the combination of an ACEi and ARB results in improvement in TG and VLDL+IDL in patients with DN. However, despite significant reductions in albuminuria after maximally dosed ACEi, further reductions in albuminuria with either losartan or spironolactone did not improve total or LDL cholesterol profiles. Study subjects assigned to losartan improved dyslipidemic profiles in TG and TG-rich lipoproteins (VLDL+IDL) when compared with placebo or spironolactone. Levels of VLDL+IDL also decreased suggesting a reduction in the particle number of these lipoproteins.

To our knowledge, this is the first study to demonstrate an improvement in TG and VLDL+IDL in patients with DN combining an ARB (losartan) with an ACEi (lisinopril). The study design controlled for factors that affect protein excretion in diabetes including blood pressure, sodium and protein intake, and glycemia. There were no differences in blood pressure, protein and sodium intake or glycemia among groups during the 48 weeks of the study. ${ }^{20}$
Improvement in TG and VLDL+IDL with the concomitant reduction in ApoB levels potentially implicates properties specific to losartan, which may improve dyslipidemia independent of albuminuria reduction, and suggests an effect of losartan on TG metabolism.

Keilani et $a l^{17}$ demonstrated amelioration of TC and LDL cholesterol during treatment with fosinopril (ACEi) associated with improvement in proteinuria, which was not observed in our study. However, it is worth noting that Keilani et al studied fewer subjects, only those with nephrotic-range proteinuria and included diabetic and nondiabetic (40\%)-related nephropathies. Ruggenenti et al demonstrated a dose response relationship with ACEi and improvement in TC, LDL, and TG. However, their study included 28 patients and all with non-diabetic kidney disease. ${ }^{19}$ Both studies suggested that amelioration of proteinuria were the likely underlying causes of improvement in lipid profiles yet neither of these studies carefully evaluated the lipoprotein composition and particle size for LDL.

Previous studies discuss the possibility of inherent qualities of ARBs that can improve dyslipidemia. Kyvelou et al showed the effect of six different ARBs on plasma TC, LDL, TC/HDL, ApoB, and TG. Losartan improved TC, LDL, TC/HDL, ApoB, while only valsartan and losartan improved TG. ${ }^{23}$ Notably, the study looked at hypertensive patients only and excluded any patient with kidney disease. Lerch et al tested the effect of losartan on insulin sensitivity, lipid profiles, and plasma endothelin in normotensive offspring of hypertensive parents. They demonstrated no effect of ARB on insulin sensitivity, but did see a significant 


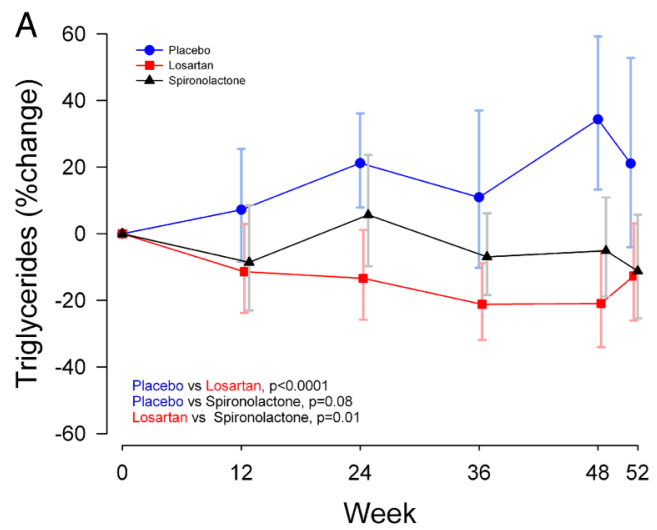

B
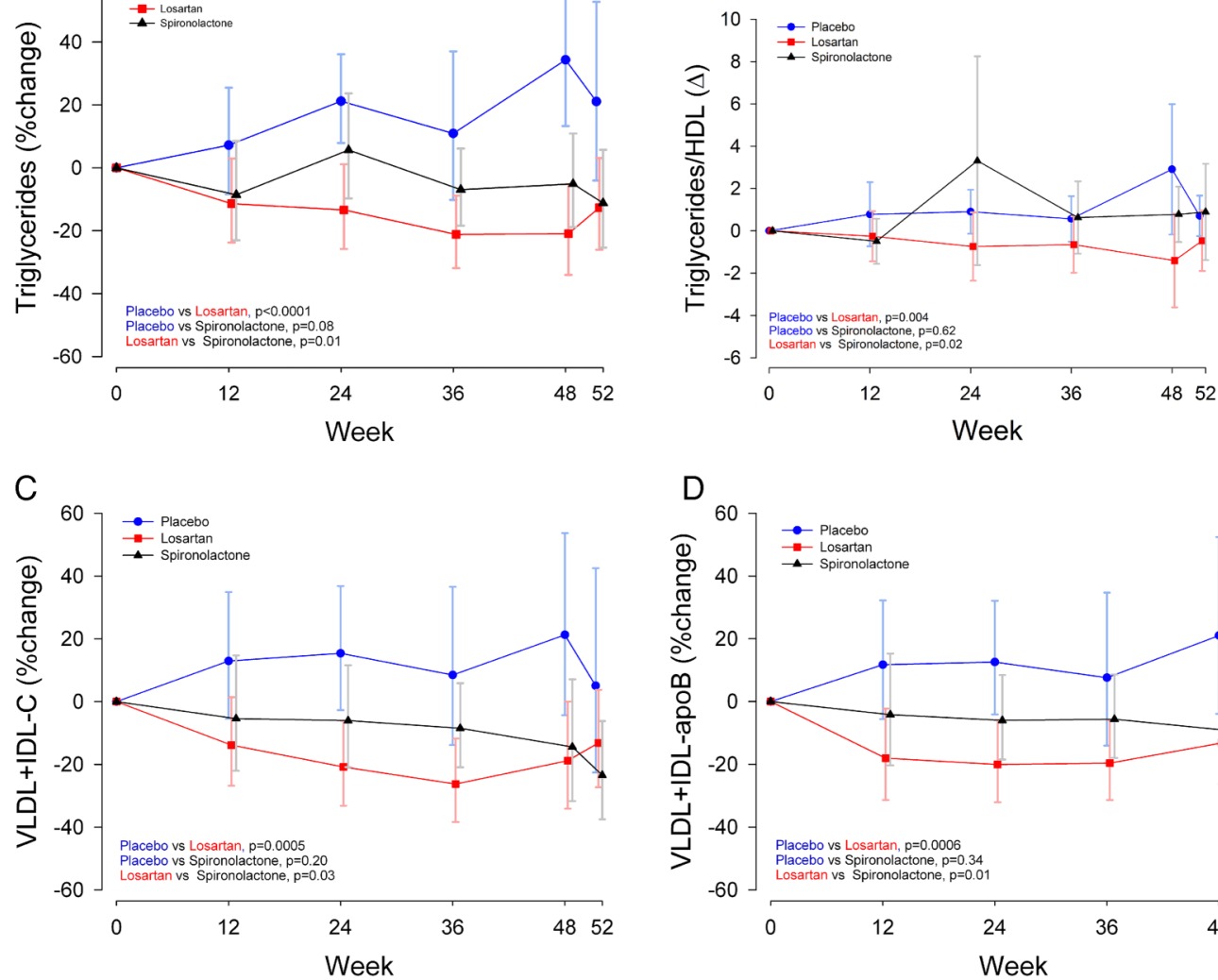

Figure 1 (A) Per cent change of plasma triglycerides by treatment group triglyceride per cent change at week $48:+34.3 \%$ (placebo), $20.9 \%$ (losartan), $-5.1 \%$ (spironolactone). (B). Absolute change in plasma triglyceride/HDL-cholesterol ratio by treatment group triglyceride/HDL per cent change at week $48:+2.9 \%$ (placebo), $-1.4 \%$ (losartan), $+0.8 \%$ (spironolactone). (C) Per cent change of very-low-density lipoprotein cholesterol (VLDL-C)+intermediate-density lipoprotein cholesterol (IDL)-C V+l-C by treatment group. Per cent change at week 48: $+34.3 \%$ (placebo), $-18.8 \%$ (losartan), $-14.4 \%$ (spironolactone). (D) Per cent change of very-low-density lipoprotein $\mathrm{ApoB}(\mathrm{V}-\mathrm{ApoB})+$ intermediate-density lipoprotein $\mathrm{ApoB}(\mathrm{I}-\mathrm{ApoB})$ by treatment group. Per cent change at week $48:+21.0 \%$ (placebo), $-13.2 \%$, (losartan), $-9.2 \%$ (spironolactone). The figures depict geometric mean $(95 \% \mathrm{Cl})$. p Values are from mixed-model repeated-measures analysis comparing treatment groups. Apo-B, apolipoprotein B.

reduction in serum total cholesterol and total TG levels. ${ }^{24}$ In the present study, the losartan group displayed a trend for improvement in total plasma-ApoB and LDL-ApoB that was not statistically significant. Derosa et al demonstrated improvement in lipid profiles with telmisartan as compared with eprosartan in 119 hypertensive patients with only diet controlled type 2 diabetes without albuminuria. ${ }^{25}$

The mechanism(s) by which ARB administration may improve dyslipidemia is incompletely understood, but Benson et al suggested that the ARB telmisartan may act as a partial agonist to the PPAR-gamma receptor and thereby improve lipid profiles. They speculated that this effect may be due to unique molecular structural properties of telmisartan, not shared by other ARB. ${ }^{26}$ Additionally, angiotensin II may stimulate macrophage-induced lipid oxidation due to lipid peroxidation via AT1 receptor upregulation. ${ }^{27}$ Therefore, it is possible that ARBs reduce the production of VLDL by improved insulin resistance along with diversion of fatty acids from the liver as speculated in some animal models. ${ }^{28}$ For example, Fogari et al demonstrated improvement in insulin sensitivity and hepatic steatosis in hypertensive, obese patients receiving losartan compared with amlodipine. ${ }^{29}$
Patients with DN are at high risk for CVD and have a high prevalence of dyslipidemia and hypertension. Among patients with DN, improvement in albuminuria is strongly associated with reduction in the risk for developing ESRD. While larger randomized controlled trials, such as ONTARGET and VA NEPHRON-D demonstrated more side effects with dual renin-angiotensin-aldosterone (RAAS) blockade, neither study targeted albuminuria nor dyslipidemia. ${ }^{30}{ }^{31}$ Large-scale clinical trials targeting albuminuria and lipid profiles in patients with $\mathrm{DN}$ are needed to determine whether dual RAAS blockade improves dyslipidemia and important clinical outcomes, such as mortality, myocardial infarction, and ESRD. Bakris et $a l^{32}$ recently demonstrated that dual blockade of RAAS with ACEi or ARB and a novel non-steroidal MRA, finerenone, reduces albuminuria in patients with type 2 diabetes mellitus and kidney disease. Two large-scale phase III clinical trials using this agent examining cardiovascular and renal outcomes are now underway (ClinicalTrials.gov Identifiers: NCT02540993, NCT02545049). Given the clinical correlations with dyslipidemia and DN with and without nephrotic-range proteinuria, it is important to characterize effective methods to improve their dyslipidemia to decrease the risk of cardiovascular mortality and CKD progression. If 
ARB can effectively ameliorate albuminuria and lipid profiles, it will continue to be an important treatment to reduce the risk of progression to ESRD and CVD. Our findings suggest, but do not prove, that the beneficial effect of losartan on dyslipidemia is not mediated solely through a reduction in albuminuria.

Our study has some limitations to consider. First, the fraction of subjects who did not complete the 48 weeks of study was higher in the losartan and spironolactone groups. Analysis demonstrated that the baseline characteristics were similar between those who completed and those who did not complete the study. Second, approximately two-thirds of the patients were on statin drug therapy. To minimize the effect of statins on interpretation of our study, we required that statin dose remain constant during the study without addition of new statin therapy during the study, and notably the fraction of subjects on a statin was nearly identical at randomization (table 1). Last, we did not require that patients follow a synthetic diet to ensure that daily intake of cholesterol and fat was constant during the study. However, we did prescribe a constant diet restricted in cholesterol and total fat.

In summary, we found long-term administration of losartan $100 \mathrm{mg}$, but not spironolactone $25 \mathrm{mg}$ once daily added onto lisinopril $80 \mathrm{mg}$ once daily improved TG and VLDL+IDL cholesterol levels as well as their respective Apo B levels in patients with DN. The potentially beneficial effect of lipid lowering observed using losartan was not explained solely on the basis of albuminuria reduction. Our findings are consistent with previous studies demonstrating that ARB administration may improve plasma lipid and lipoprotein composition in patients with hypertension and diabetes. We speculate that losartan, independent of the antiproteinuric effect, improves dyslipidemia by reducing hepatic VLDL production or improving VLDL catabolism (or a combination of the two). Further studies are required to clarify the mechanism. While the losartan group demonstrated a modest reduction in TGs, further studies should elucidate the effect of losartan with the addition of remnant lipoprotein-lowering agents, such as fibrates or fish oil, and their relationship with important cardiovascular end points. Amelioration of albuminuria and dyslipidemia with the use of an ARB could be an important tool in reducing the risk of progression to ESRD and developing cardiovascular complications.

Acknowledgments The authors would like to thank Ms Tammy Lightfoot, Nancy Wang, Biman Pramanik, Elizabeth Tullos, and Martha Cruz for assisting in the conduct of the study including data collection and analysis and the Nephrology Clinical and Translational Research Center at UT Southwestern.

Contributors The coauthors have all contributed to this manuscript and approved of this submission. Neither this manuscript nor any significant part of it is under consideration for publication elsewhere or published or available elsewhere in a manner that could be construed as a prior or duplicate publication of the same or substantially overlapping content.

Funding This work was supported by the following NIH grants: NCATS UL1TR000451, NIDDK 3R01DK063010-04S1 and NIDDK George M. O'Brien Center P30DK079328.

Competing interests None declared.

Ethics approval University of Texas Southwestern Medical Center Institutional Review Board.

Provenance and peer review Not commissioned; externally peer reviewed.

Open Access This is an Open Access article distributed in accordance with the Creative Commons Attribution Non Commercial (CC BY-NC 4.0) license, which permits others to distribute, remix, adapt, build upon this work noncommercially, and license their derivative works on different terms, provided the original work is properly cited and the use is non-commercial. See: http:/l creativecommons.org/licenses/by-nc/4.0/

\section{REFERENCES}

1 Adler S. Diabetic nephropathy: linking histology, cell biology, and genetics. Kidney Int 2004;66:2095-106

2 Adler Al, Stevens RJ, Manley SE, et al. Development and progression of nephropathy in type 2 diabetes: the United Kingdom Prospective Diabetes Study (UKPDS 64). Kidney Int 2003;63:225-32.

3 Keith DS, Nichols GA, Gullion CM, et al. Longitudinal follow-up and outcomes among a population with chronic kidney disease in a large managed care organization. Arch Intern Med 2004;164:659-63.

4 Gaede P, Vedel P, Larsen N, et al. Multifactorial intervention and cardiovascular disease in patients with type 2 diabetes. N Engl I Med 2003;348:383-93.

5 Ordonez JD, Hiatt RA, Killebrew EJ, et al. The increased risk of coronary heart disease associated with nephrotic syndrome. Kidney Int 1993:44:638-42.

6 Vogt L, Laverman GD, Dullaart RP, et al. Lipid management in the proteinuric patient: do not overlook the importance of proteinuria reduction. Nephrol Dial Transplant 2004;19:5-8.

7 Packard CJ, Saito Y. Non-HDL cholesterol as a measure of atherosclerotic risk. I Atheroscler Thromb 2004;11:6-14.

8 Joven J, Villabona C, Vilella E, et al. Abnormalities of lipoprotein metabolism in patients with the nephrotic syndrome. N Engl J Med 1990;323:579-84.

9 Warwick GL, Caslake MJ, Boulton-Jones JM, et al. Low-density lipoprotein metabolism in the nephrotic syndrome. Metab Clin Exp 1990;39:187-92.

10 Muls E, Rosseneu M, Daneels R, et al. Lipoprotein distribution and composition in the human nephrotic syndrome. Atherosclerosis 1985:54:225-37.

11 Tseng $\mathrm{CH}$. Differential dyslipidemia associated with albuminuria in type 2 diabetic patients in Taiwan. Clin Biochem 2009;42:1019-24.

12 de Sain-van der Velden MG, Kaysen GA, Barrett HA, et al. Increased VLDL in nephrotic patients results from a decreased catabolism while increased LDL results from increased synthesis. Kidney Int 1998;53:994-1001.

13 Keane WF, Kasiske BL. Hyperlipidemia in the nephrotic syndrome. N Engl J Med 1990;9:603-4.

14 Hadjadj S, Duly-Bouhanick B, Bekherraz A, et al. Serum triglycerides are a predictive factor for the development and the progression of renal and retinal complications in patients with type 1 diabetes. Diabetes Metab 2004;30:43-51.

15 Cusick M, Chew EY, Hoogwerf B, et al. Risk factors for renal replacement therapy in the Early Treatment Diabetic Retinopathy Study (ETDRS), Early Treatment Diabetic Retinopathy Study Report No. 26. Kidney Int 2004;66:1173-9.

16 Gansevoort RT, Sluiter WJ, Hemmelder MH, et al. Antiproteinuric effect of blood-pressure-lowering agents: a meta-analysis of comparative trials. Nephrol Dial Transplant 1995;10:1963-74.

17 Keilani T, Schlueter WA, Levin ML, et al. Improvement of lipid abnormalities associated with proteinuria using fosinopril, an angiotensin-converting enzyme inhibitor. Ann Intern Med 1993;118:246-54.

18 Wapstra FH, Van Goor H, Navis G, et al. Antiproteinuric effect predicts renal protection by angiotensin-converting enzyme inhibition in rats with established adriamycin nephrosis. Clin Sci 1996;90:393-401.

19 Ruggenenti P, Mise N, Pisoni R, et al. Diverse effects of increasing lisinopril doses on lipid abnormalities in chronic nephropathies. Circulation 2003;107:586-92.

20 Mehdi UF, Adams-Huet B, Raskin P, et al. Addition of angiotensin receptor blockade or mineralocorticoid antagonism to maximal angiotensin-converting enzyme inhibition in diabetic nephropathy. I Am Soc Nephrol 2009;20:2641-50

21 Vega GL, Grundy SM. Quantitation of apolipoprotein B by chemical methods. Meth Enzymol 1996;263:63-82.

22 Vega GL, Cater NB, Hadizadeh DR III, et al. Free fatty acid metabolism during fenofibrate treatment of the metabolic syndrome. Clin Pharmacol Ther 2003;74:236-44

23 Kyvelou SM, Vyssoulis GP, Karpanou EA, et al. Effects of antihypertensive treatment with angiotensin II receptor blockers on lipid profile: an open multi-drug comparison trial. Hellenic J Cardiol 2006;47:21-8.

24 Lerch M, Teuscher AU, Beissner $\mathrm{P}$, et al. Effects of angiotensin II-receptor blockade with losartan on insulin sensitivity, lipid profile, and endothelin in normotensive offspring of hypertensive parents. I Cardiovasc Pharmacol 1998:31:576-80. 
25 Derosa G, Ragonesi PD, Mugellini A, et al. Effects of telmisartan compared with eprosartan on blood pressure control, glucose metabolism and lipid profile in hypertensive, type 2 diabetic patients: a randomized, double-blind, placebo-controlled 12-month study. Hypertens Res 2004;27:457-64.

26 Benson $\mathrm{SC}$, Pershadsingh $\mathrm{HA}, \mathrm{Ho} \mathrm{Cl}$, et al. Identification of telmisartan as a unique angiotensin II receptor antagonist with selective PPARgamma-modulating activity. Hypertension 2004:43:993-1002.

27 Keidar S, Kaplan M, Hoffman A, et al. Angiotensin II stimulates macrophage-mediated oxidation of low density lipoproteins. Atherosclerosis 1995;115:201-15.

28 Sugimoto K, Kazdova L, Qi NR, et al. Telmisartan increases fatty acid oxidation in skeletal muscle through a peroxisome proliferator-activated receptor-gamma dependent pathway. J Hypertens 2008;26:1209-15.
29 Fogari R, Maffioli P, Mugellini A, et al. Effects of losartan and amlodipine alone or combined with simvastatin in hypertensive patients with nonalcoholic hepatic steatosis. Eur I Gastroenterol Hepatol 2012;24:164-71.

30 Yusuf S, Teo KK, Pogue J, et al. Telmisartan, ramipril, or both in patients at high risk for vascular events. N Engl I Med 2008; 358:1547-59.

31 Fried LF, Emanuele N, Zhang $\mathrm{JH}$, et al. Combined angiotensin inhibition for the treatment of diabetic nephropathy. N Engl J Med 2013;369:1892-903.

32 Bakris GL, Agarwal R, Chan JC, et al. Effect of finerenone on albuminuria in patients with diabetic nephropathy: a randomized clinical trial. JAMA 2015:314:884-94 